\title{
Suicide among Danes with multiple sclerosis
}

\section{H Brønnum-Hansen, E Stenager, E Nylev Stenager, N Koch-Henriksen}

\begin{abstract}
Objective: To compare the suicide risk among Danish citizens with multiple sclerosis with that of the general population, and to evaluate changes over 45 years.

Methods: The study was based on linkage of the Danish Multiple Sclerosis Registry to the Cause of Death Registry. It comprised all 10174 persons in whom multiple sclerosis was diagnosed in the period 1953 to 1996. The end of follow up was 1 January 1999. Standardised mortality ratios (SMRs) were calculated for various times after diagnosis and for age and calendar period of diagnosis.

Results: In all, 115 persons (63 men, 52 women) had taken their own lives, whereas the expected number of suicides was 54.2 (29.1 men, 25.1 women). Thus the suicide risk among persons with multiple sclerosis was more than twice that of the general population $(S M R=2.12)$. The increased risk was particularly high during the first year after diagnosis (SMR = 3.15).

Conclusions: The risk of suicide in multiple sclerosis was almost twice as high as expected more than 20 years after diagnosis. The excess suicide risk has not declined since 1953.
\end{abstract}

M ultiple sclerosis is associated with an increased risk of death. Recently, we reported that the mortality in Danes with multiple sclerosis was almost three times that of the general population. ${ }^{1}$ The excess mortality was caused by death from all major disease groups except cancer, and by accidents and suicide. Multiple sclerosis is associated with psychological problems, depression being the commonest mental disorder, often related to aggravation of the disease. $^{2-5}$ Increased risks for depression and suicide are known to be associated with certain medical disorders. ${ }^{6-8}$ Not only can a diagnosis of a severe chronic disorder provoke a mental crisis, but some neurological diseases may in themselves affect a person's mental condition and lead to comorbid depression, independent of the formal diagnosis. Thus it is reasonable to expect an increased risk for suicide among persons with multiple sclerosis.

The results of studies of suicide risk in multiple sclerosis are inconsistent, and comparisons are often impossible owing to different study designs and methodological problems. ${ }^{9}$ A study based on the Danish Multiple Sclerosis Registry found that the suicide risk among persons with multiple sclerosis was twice that of the general population, ${ }^{10}$ and a recent study from Sweden found that the risk was 2.3 times higher among persons with multiple sclerosis than in the general population. ${ }^{11}$ A much higher excess mortality from suicide was found in two regions of Canada, ${ }^{12}$ whereas a Finnish study reported no increased risk among persons with multiple sclerosis. $^{13}$

We updated the previous Danish study ${ }^{10}$ and evaluated whether the suicide risk among persons with multiple sclerosis has changed since the mid-1900s. The longer follow up enabled us to examine the suicide risk among persons with prolonged disease.

\section{METHODS}

The Danish Multiple Sclerosis Registry was established as a continuation of a prevalence survey conducted in $1956 .{ }^{14}$ The register includes information about persons in Denmark in whom multiple sclerosis was diagnosed after 1921 and who were alive in 1948 or who experienced onset of the disease in the period 1949 to 1996 and were notified before 1997. Virtually all Danish residents in whom multiple sclerosis was diagnosed by a neurologist or in a department of neurology are registered, and the cases are subsequently reviewed and classified, according to the criteria of Allison and Millar ${ }^{15}$ for those with onset before 1994 and according to the Poser criteria $^{16}$ for those with onset after 1 January 1994. Details of data collection and the validity of the register have been published elsewhere. ${ }^{17}$ The persons included in the present study were classified as having clinically definite, probable, or possible multiple sclerosis according to the diagnostic criteria.

Data on emigration and death were obtained by record linkage to the Danish civil registration system established in 1968 and the Cause of Death Registry, which has data on all deaths since $1943 .{ }^{18}$ The end of follow up for cause specific mortality was 1 January 1999. Data on deaths and causes of death in the Danish population, distributed by sex, age, and calendar year, were derived from the same official registers. As it was not possible to distinguish between death from suicide and death from accidents in 1951 and 1952 in the Cause of Death Registry records, the observation period for diagnoses of multiple sclerosis was restricted to 1953 to 1996. The expected number of suicides in the general population was estimated for each sex by multiplying the age and time specific person-years of observation by the similar age and time specific population suicide rate. Standardised mortality ratios (SMRs) - that is, the quotient of the observed to the expected numbers of deaths-were estimated and 95\% confidence intervals (CI) were established, assuming that the numbers of suicides followed a Poisson distribution.

\section{RESULTS}

The study included 10174 persons (4061 men and 6113 women) in whom multiple sclerosis was diagnosed between 1953 and 1996, corresponding by systematic follow up to 160401 person-years. In all, 115 persons with multiple sclerosis (63 men and 52 women) had committed suicide before 1 January 1999, whereas the expected number of suicides in a matched general population was 54.2 (29.1 men and 25.1 women). Overall, the suicide risk of persons with multiple sclerosis was slightly more than twice that of the general population. Thus the SMR was 2.12 (95\% CI, 1.75 to 2.55 ) for the whole group, 2.16 (1.66 to 2.77) for men, and 2.07 ( 1.55 to 2.72 ) for women (table 1). The excess suicide rate during the first 15 years after diagnosis was relatively stable for men (SMR varying between 2.18 and 2.76), but

Abbreviations: SMR, standardised mortality ratio 
Table 1 Standardised mortality ratios (SMRs) for suicide by sex and years after diagnosis of multiple sclerosis

\begin{tabular}{llll}
\hline \multirow{2}{*}{$\begin{array}{l}\text { Years after } \\
\text { diagnosis }\end{array}$} & \multicolumn{2}{l}{ SMR $(95 \%$ confidence interval) } & \\
\cline { 2 - 4 } & Men & Women & Both sexes \\
\hline 0 to 1 & $2.47(0.67$ to 6.32$)$ & $4.03(1.31$ to 9.41$)$ & $3.15(1.44$ to 5.97$)$ \\
1 to 5 & $2.18(1.19$ to 3.66$)$ & $2.62(1.40$ to 4.48$)$ & $2.37(1.56$ to 3.45$)$ \\
5 to 10 & $2.76(1.66$ to 4.31$)$ & $2.18(1.13$ to 3.80$)$ & $2.50(1.70$ to 3.55$)$ \\
10 to 15 & $2.29(1.18$ to 3.99$)$ & $1.78(0.77$ to 3.50$)$ & $2.05(1.25$ to 3.17$)$ \\
15 to 20 & $1.33(0.43$ to 3.10$)$ & $0.85(0.18$ to 2.49$)$ & $1.10(0.47$ to 2.16$)$ \\
20 to 45 & $1.74(0.80$ to 3.31$)$ & $2.04(1.02$ to 3.65$)$ & $1.89(1.16$ to 2.93$)$ \\
0 to 45 & $2.16(1.66$ to 2.77$)$ & $2.07(1.55$ to 2.72$)$ & $2.12(1.75$ to 2.55$)$ \\
\hline
\end{tabular}

that for women it was higher-although not significantly so-in the first year after diagnosis $(S M R=4.03)$ than in subsequent periods (SMR declining to 1.78). The risk was lowest 15 to 20 years after diagnosis $(\mathrm{SMR}=1.33$ for men, 0.85 for women) and then tended to rise again to almost twice the risk of the general population $(\mathrm{SMR}=1.74$ for men, 2.04 for women).

Figure 1 shows estimates of the cumulative suicide hazard rates for men and women with multiple sclerosis (with 95\% confidence intervals) and for the matched general male and female population. The figure shows higher suicide rates among men than women with multiple sclerosis, as for Danish men and women in general.

The SMR for suicide among persons aged less than 30 at the time of diagnosis was 2.55 for both sexes; those for persons aged 30 to 39 at diagnosis were 2.82 for men and 2.79 for women. Persons who were 40 or older when multiple sclerosis was diagnosed had a lower excess risk of suicide $(\mathrm{SMR}=1.52)$, which was statistically significantly lower than for persons in whom multiple sclerosis was diagnosed when they were aged 30 to 39.

The excess suicide risk did not change significantly during the observation period, but tended to increase at the end of the period. Thus SMR estimates for persons in whom multiple sclerosis was diagnosed in 1953-1961, 1962-1970, 1971-1979, and 1980-1988 and who were followed up for 10 years were $2.22,2.32,1.73$, and 3.24, respectively.

\section{DISCUSSION}

The suicide risk among Danes in general is higher for men than for women, ${ }^{19}$ and this was also true for Danes with multiple sclerosis. We found no clear overall difference in the excess risk between men and women with multiple sclerosis, although apparently a higher excess suicide risk was seen shortly after diagnosis among women but not among men.

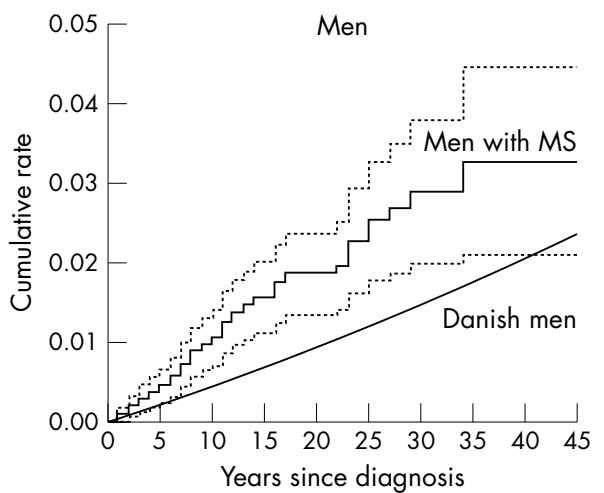

Even so, the suicide risk is slightly higher among men than among women with multiple sclerosis in the first year after diagnosis.

The exceptionally long follow up allowed us to evaluate the excess suicide risk among persons with long term disease, including those who were severely affected, with a high degree of disability. The SMR was higher for persons in whom multiple sclerosis had been diagnosed more than 20 years previously than for those who received their diagnosis 15 to 20 years previously, probably because patients typically experience the most serious physical and social consequences of their disease 20 years or more after the diagnosis. The difference was, however, not statistically significant. The overall conclusion from previous studies of suicide risk among persons with multiple sclerosis is that the risk is highest shortly after diagnosis. ${ }^{10}{ }^{11}$ We found that the risk is still high many years after diagnosis, as was reported in a retrospective study. ${ }^{20}$

We were unable to examine the effect of progression of the disease on the suicide risk. Some characteristics of the previously reported suicides were identified..$^{21}$ Thus men with multiple sclerosis who were at the highest risk of taking their own lives were characterised by previous mental disorders, previous suicidal behaviour, depression, recent deterioration of health owing to multiple sclerosis, and moderate disability, while the characteristics of women with multiple sclerosis were less clear. An examination of suicidal intent in persons with multiple sclerosis identified social isolation, major depression, and alcohol abuse as predictors. ${ }^{22}$ Alteration of the personality leading to suicide may also be a direct result of brain lesions caused by multiple sclerosis. This could theoretically happen even before a diagnosis of multiple sclerosis is made, and then the disease would escape registration. However, in all nine cases of suicide in multiple sclerosis in which a necropsy examination was carried out,

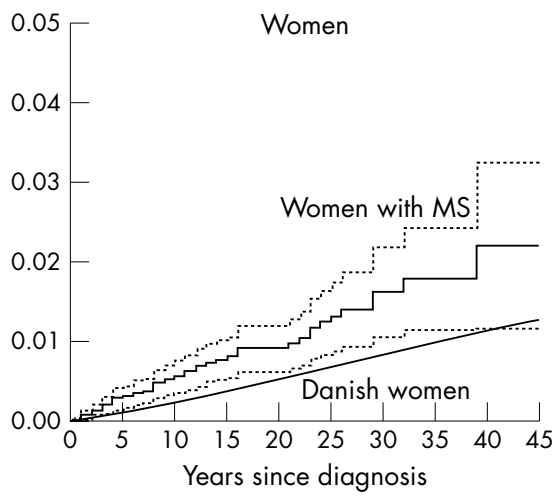

Figure 1 Estimated cumulative suicide rates of Danes with multiple sclerosis (MS) and of the matched general population. Broken lines are 95\% confidence limits. 
the multiple sclerosis diagnosis was established before the suicide. The time between onset and diagnosis did not differ between persons who committed suicide and those who did not, and the inclusion of the time lag in the analysis did not indicate that disease duration before the diagnosis affected the risk of suicide.

The possibility of depression in persons with multiple sclerosis might be overlooked by primary care physicians, even though depression is extremely common. The results of our study stress the importance of looking for depressive symptoms both immediately after the onset or diagnosis of multiple sclerosis and also in later stages of the disease.

\section{ACKNOWLEDGEMENTS}

The Danish Multiple Sclerosis Society finances the Danish Multiple Sclerosis Registry.

\section{Authors' affiliations}

H Brønnum-Hansen, National Institute of Public Health, Copenhagen, Denmark

E Stenager, N Koch-Henriksen, The Danish Multiple Sclerosis Registry, Rigshospitalet, Copenhagen

E Nylev Stenager, Institute of Public Health, University of Southern

Denmark, Odense, Denmark

Competing interests: none declared

Correspondence to: Henrik Brønnum-Hansen, National Institute of Public Health, Øster Farimagsgade 5, DK-1399 Copenhagen K, Denmark; hbh@niph.dk

Received 22 October 2004

In revised form 4 January 2005

Accepted 24 January 2005

\section{REFERENCES}

1 Brønnum-Hansen H, Koch-Henriksen N, Stenager E. Trends in survival and cause of death in Danish patients with multiple sclerosis. Brain 2004; 127:844-50.
2 Mclvor GP, Riklan M, Reznikoff $M$. Depression in multiple sclerosis as a function of length and severity of illness, age, remissions, and perceived social support. J Clin Psychol 1984;40:1028-33.

3 Sadovnick AD, Remick RA, Allen J, et al. Depression and multiple sclerosis. Neurology 1996;46:628-32.

4 Fisk JD, Morehouse SA, Brown MG, et al. Hospital-based psychiatric service utilization and morbidity in multiple sclerosis. Can J Neurol Sci 1998;25:230-5.

5 Chwastiak L, Ehde DM, Gibbons LE, et al. Depressive symptoms and severity of illness in multiple sclerosis: epidemiologic study of a large community sample. Am J Psychiatry 2002;159:1862-8.

6 Harris EC, Barraclough BM. Suicide as an outcome for medical disorders. Medicine 1994;73:281-96.

7 Kleespies PM, Hughes DH, Gallacher F. Suicide in the medically and terminally ill: psychological and ethical considerations. J Clin Psychol 2000;56:1153-71.

8 Stenager EN, Stenager E. Physical illness and suicidal behaviour. In: Hawton K, van Heeringen K, eds. The international handbook of suicide and suicide attempt. London: John Wiley and Sons, 2000:403-20.

9 Stenager EN, Stenager E. Suicide and patients with neurologic diseases. Methodologic problems. Arch Neurol 1992;49:1296-303.

10 Stenager EN, Stenager E, Koch-Henriksen N, et al. Suicide and multiple sclerosis: an epidemiological investigation. I Neurol Neurosurg Psychiatry 1992:55:542-5.

11 Fredrikson S, Cheng Q, Jiang GX, et al. Elevated suicide risk among patients with multiple sclerosis in Sweden. Neuroepidemiology 2003;22:146-52.

12 Sadovnick AD, Eisen RN, Ebers GC, et al. Cause of death in patients attending multiple sclerosis clinics. Neurology 1991;41:1193-6.

13 Sumelahti M-L, Tienari PJ, Wikstrom J, et al. Survival of multiple sclerosis in Finland between 1964 and 1993. Mult Scler 2002;8:350-5.

14 Hyllested K. Disseminated sclerosis in Denmark: prevalence and geographical distribution. Copenhagen: J Jørgensen, 1956:1-141.

15 Allison RS, Millar JDH. Prevalence and familial incidence of disseminated sclerosis. Ulster Med J 1954;23(suppl 2):5-49.

16 Poser CM, Paty DW, Scheinberg L, et al. New diagnostic criteria for multiple sclerosis: guidelines for research protocols. Ann Neurol 1983;13:227-31.

17 Koch-Henriksen N, Rasmussen S, Stenager E, et al. The Danish Multiple Sclerosis Registry. History, data collection and validity. Dan Med Bull $2001 ; 48: 91-4$

18 Juel K, Helweg-Larsen K. The Danish registers of causes of death. Dan Med Bull 1999;46:354-7.

19 Helweg-Larsen K, Juel K. Sex differences in mortality in Denmark during half a century, 1943-92. Scand J Public Health 2000;28:214-21.

20 Berman A, Samuels L. Suicide among people with multiple sclerosis. J Neurol Rehabil 1993;7:53-62.

21 Stenager EN, Koch-Henriksen N, Stenager E. Risk factors for suicide in MS. Psychother Psychosom 1996;65:86-90.

22 Feinstein A. An examination of suicidal intent in patients with multiple sclerosis. Neurology 2002;59:674-8. 